\title{
Adaptive fuzzy sliding mode controller design for PMLSM position control
}

\author{
Khadidja Makhloufi, Ismail Khalil Bousserhane, Si Ahmed Zegnoun \\ Departement of Electrical Engineering, University Tahri Mohamed of Bechar, Bechar, Algeria
}

\begin{tabular}{l} 
Article Info \\
\hline Article history: \\
Received Apr 9, 2020 \\
Revised Mar 2, 2021 \\
Accepted Apr 18, 2021 \\
\hline Keywords: \\
Adaptive fuzzy sliding mode \\
control \\
Chattering phenomenon \\
Indirect field-oriented control \\
Sliding mode control \\
Permanent magnet linear \\
synchronous motor
\end{tabular}

\section{Corresponding Author:}

Khadidja. Makhloufi

Departement of Electrical Engineering

Smart grid \& Renewable Energy Laboratory

University Tahri Mohamed of Bechar, B.P 417 Bechar 08000, Algeria

Emai : nourelwissal@gmail.com

\begin{abstract}
We focus a modern methodology in this paper for adding the fuzzy logic control as well as sliding model control. This combination can enhance the PMLSM position control robustness and enhanced performance of it. In the start, for an application in an area to control the loops placement and position for the synchronous motor what has permanent magnetic linearity we tend to control the fuzzy sliding mode control. To resolve the chattering issues a designed controller is investigated and, in this way, steady state motion in sliding with higher accuracy is obtained. In this case, method of online tuning with the help of fuzzy logic is used in order to adjust the thickness of boundary layer and switching gains. For the suggested scheme technique, the outcomes of simulation suggest that with the classical SMC the accurate state and good dynamic performance is compared due to force chattering resistance, response by quick dynamic force and external disturbance elements and robustness against them.
\end{abstract}

This is an open access article under the CC BY-SA license.

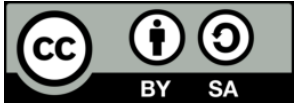

\section{INTRODUCTION}

Linear motions of higher speed and accuracy are needed by modern control systems as equipment of manufacturing, transporting and robots. With the help of rotary motors with the mechanism of transmission, the linear motion is implemented traditionally in such a way that there is a reduction in gears and leading screws. Like mechanical transmission, there are a lot of industrial products that fail to reduce the position of linear motion along with dynamic response. On the other hand, they introduce backlash, the loads with large friction and inertia [1]. Most of the times, high speed and modern and most newly constructed semi conductors need higher accuracy motions and other equipments for manufacturing, X-Y driving gadgets, artificial hearts and robots. [2]-[4].

The permanent, magnetic synchronous and linear motions have plenty of advantages and this is the reason of their extensive use in making industrial scale robots, equipments for manufacturing, instruments for various machines, photolithographic machines etc. High controllability and higher thrust density are some of the main features of PMLSM along with responsive dynamics, lesser losses, superior dynamic working, and precision in its high positioning with the simplicity of their mechanical structure. On the other hand, the significant effects of model uncertainties and external disturbances are caused by the suppression of mechanical transmission parts. [1], [5], [6]. Hence, we can say that for PMLSM devices a significant role is played by the design of a controller and load disturbance compensator. For the improvement of PMLSM many investigative workers have created advanced control methods and they all are expected to enhance the 
performance drive. [1], [3], [7], [8]. In the same way, various kinds of observational algorithms are added as well to maintain the equilibrium of the external disturbance load and its evaluation. For the PMSLM control of position, some methods are highly successful such as back stepping, exact linearization and adaptive controlling methods. [3], [5].

For the higher performance of control methods and permanent magnetic linear and synchronous motor the field-oriented technique is extensively used and this technique can provide the best and similar performance, which one can get via DC machines excitedly separate. [5], [9]. For this objective to be achieved, we need to keep the value of rotor force equal to normal value in such a way that the maximum power efficiency is ensured by the optimal magnetic circuit and its contemporarily exploitation. On the other hand, the dependency of PMLSM in IFOC scheme is the bigger disadvantage. The PMLSM is dependent on motor parameter variations due to heat, level of saturation and effects on skin. [5]. Specifically speaking, the IFOC control scheme is influenced to a great extent by the primary resistance as a main parameter and due to ohm's heat, it is changing widely. [3], [10].

Based on order reduction the sliding mode control due to the characteristics of its strong robustness and rejection disturbances are obtained. These make the implementation of power converters easier and some of the electrical machines depend on its prospective control methods. [11], [12]. Since the communication is implied between the controllers, SMC is a type of variable structure scheme. Two steps are there in all the designed controllers for variable structures and these phases are sliding and reaching phases. [13], [14]. With the help of feedback control law at initial stage, the system is moved in the direction of switching surface. To maintain the sliding motion a term switching is used and in this by the choice of sliding surface, the system's dynamics are determined as well. Parametric uncertainties and load disturbances are some of the factors on which the sliding mode is independent of in terms of its motion. For position control of PMLSM the SMC is employed as well [8]. In the end, SMC has a discontinuous kind of switching feature nature and the control system is chattering is caused due to it. [11], [12], [15], [16]. To reduce or mitigate the chattering phenomenon effects, numerous approaches have been proposed [17]- [20].

Adaptive fuzzy controller with sliding mode is there in this paper. It has a power to combine the fuzzy logic and adaptive sliding mode for the position control of PMLSM. At the position, tracking objective under uncertainty parameter the suggested scheme is applied to arrive. The load thrust disturbance is observed as well in the magnetic linear permanent synchronous motor and this is done to reduce the phenomenon of chattering and problems of tracking trajectory. As the stability is ensured, the machine performance and its robustness are improved. The other parts of this investigative paper include the following.

The mathematical model is reviewed in the section 2 and various IFOC principles (indirect fieldoriented control) are studied for the permanent magnetic linearly synchronous motor. The development of suggestive mode control design for adaptive fuzzy sliding mode is demonstrated in Section 3 for the position control of PMLSM. The outcomes and discussions are explained in section 4 and some diagrams and results are mentioned as follows.

\section{MATHEMATIC MODEL AND VECTOR CONTROL OF PMLSM}

For the permanent magnetic linearly synchronous motor we present the mathematical model with the help of rotating frame in synchronous pattern $\mathrm{d}-\mathrm{q}$ in the form of differential equation mentioned below: (1) to (4) [1], [3], [5].

$$
\begin{aligned}
& v_{d s}=R_{s} \cdot i_{d s}+L_{d} \frac{d i_{d s}}{d t}-\frac{\pi}{\tau} P \cdot v_{d} \cdot L_{q} \cdot i_{q s} \\
& v_{q s}=R_{s} \cdot i_{q s}+L_{q} \frac{d i_{q s}}{d t}+\frac{\pi}{\tau} P \cdot v_{d} \cdot L_{d} \cdot i_{d s}+\psi \cdot P \frac{\pi}{\tau} v_{q} \\
& M \frac{d v}{d t}=F_{e}-F_{r}-D \cdot v \\
& F_{e}=\frac{3}{2} \frac{\pi}{\tau} \cdot p \cdot\left[\left(L_{d}-L_{q}\right) \cdot i_{d s} \cdot i_{q s}+\psi \cdot i_{q s}\right]
\end{aligned}
$$

The $\mathrm{d}$-axis and $\mathrm{q}$ axis currents are mentioned as $i_{d s}$ and $i_{q \sigma s}$. In the same way the $\mathrm{d}$ and $\mathrm{q}$ axis inductance is represented by $L_{d}$ and $L_{q}, \mathrm{~d}$-axis and q-axis stator voltages are represented by $v_{d}$ and $v_{q}$. The stator resistance is Rs. Polar Pitch is represented as $\tau$. Maximum flux linkage due to permanent magnet in 
each phase is represented by $\psi$. The coefficient of Damping is $\mathrm{D}$, the primary part mass is represented by $\mathrm{M}$ and polar pair number is mentioned as $P$.

The position control in the ideal fiend-oriented case can be obtained simply by the control of axis of voltage $q$ if $d$-axis current [1], [5], [9], [10]. We can describe the analogous force equation to the DC machine as follows:

$$
F_{e}=\frac{3 \pi}{2 \tau} \cdot p \cdot \psi \cdot i_{q s}^{*}
$$

So, the force can be controlled through the current $i_{q S}^{*}$ as in a DC machine. This strategy allows the synthesis of the control structure from the decoupled model of the PMLSM. The decoupling control method chooses the reference voltages must be.

$$
\left\{\begin{array}{l}
v_{d s}{ }^{*}=-P \frac{\pi}{\tau} \cdot v \cdot L_{q} \cdot i_{q s}+v_{d 0} \\
v_{q s}{ }^{*}=R_{s} \cdot i_{q s}+L_{q} \frac{d i_{q s}}{d t}+P \cdot v \frac{\pi}{\tau} \psi
\end{array}\right.
$$

The block diagram has shown in the Figure 1 presents the indirect field-oriented control (IFOC) [3], [6]-[8] of a permanent magnet linear synchronous motor.

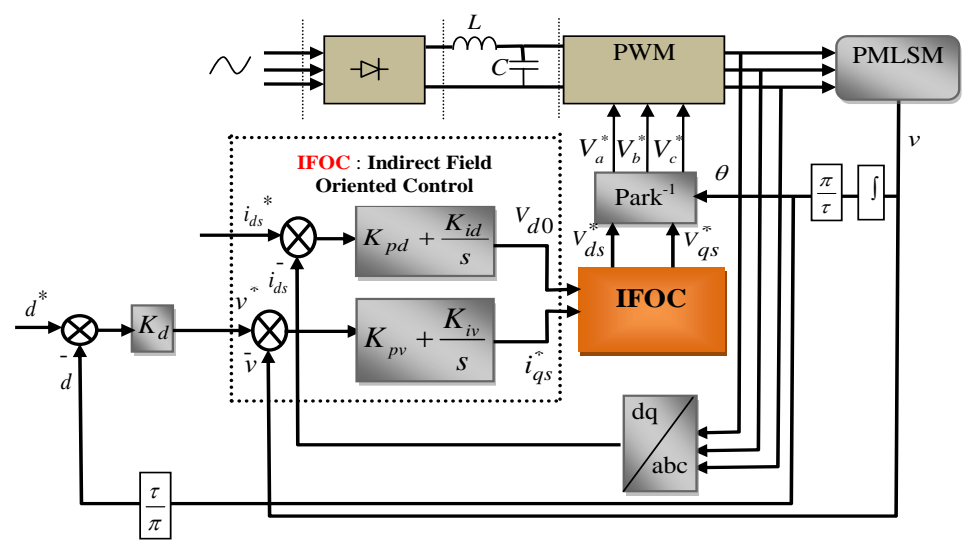

Figure 1. Block diagram of IFOC for a permanent magnet linear synchronous motor

\section{THE PROPOSED FOR ADAPTIVE FUZZY-SLIDING MODE REGULATOR}

\subsection{Sliding mode control of PMLSM}

With the sliding control mode there are some efficient and non-linear approaches which act as a strong regulator due to their structural variations. With the invariance properties of uncertainties, the system dynamics are introduced especially in the sliding mode when the dynamics of this system are controlled. [13], [14]. In the start, a sliding surface is selected for SMC design and in state variable space, the models that are desired for closed loop performances are selected. System state trajectories are forced to move ahead and the control is specially designed in this way so that the stay is possible on its surface. In the period, the trajectory of system state before even reaching to its surface of sliding is said to be the reaching phase. When the sliding phase is obtained by the trajectory of the system, the system can stay on its surface and slides to the origin of it. In the sliding model, we can see some insensitivity of the regulator device but this is not seen in the case of reaching phase. There are some uncertainties in this reaching phase and hence this phase is impacted directly by these uncertainties [7], [8], [11], [12], [15], [16], [21].

(7) is the state in which sliding surfaces are present.

$$
S(x)=\left(\frac{\partial}{\partial t}+\lambda\right)^{r-1} \cdot e(x)
$$


Employing a sign function often reasons chattering in practice. To solve this issue is by introduce a boundary layer around the switching surface [11], [15], [21]:

$$
u=u_{n}+u_{e q}
$$

Where: $u_{n}=k \cdot \operatorname{sat}(s(x) / \xi)$

Indicate the discontinuous control law part. sat (.) is a saturation function and the constant $\xi$ presents the thickness of the boundary layer are showed in (10).

$$
\operatorname{sat}\left(\frac{s(x)}{\xi}\right)=\left\{\begin{array}{lll}
\frac{s(x)}{\xi} & \text { si } & \left|\frac{s(x)}{\xi}\right|<1 \\
\operatorname{Sign}\left(\frac{s(x)}{\xi}\right) & \text { si } & \left|\frac{s(x)}{\xi}\right| \geq 1
\end{array}\right.
$$

\subsubsection{Position and current controllers design by sliding mode control}

Firstly, we define sliding surface for position control.

$$
s(d)=\lambda_{d} \cdot\left(d^{*}-d\right)+\frac{d}{d t}\left(d^{*}-d\right)
$$

Taking into account the equations of the PMLSM, the time derivative of the position sliding surface is

$$
\dot{s}(d)=\lambda_{d} \cdot \dot{d}^{*}+\ddot{d}^{*}+\left(\frac{D}{M}-\lambda_{d}\right) \cdot v+\frac{1}{M} \cdot F_{r}-\frac{3 \cdot p \cdot \psi}{2 \cdot M} \cdot \frac{\pi}{\tau} \cdot\left(i_{q s n}+i_{q s e q}\right)
$$

We take: $i_{q s}^{*}=i_{q s n}+i_{q s e q}$

During the sliding mode and at steady-state conditions, we have $s(d)=0, \dot{s}(d)=0$ and $i_{q s n}=0$, the equivalent control action can be defined as (14).

$$
i_{q s e q}=\frac{3 \cdot p \cdot \psi}{2 \cdot M} \cdot \frac{\pi}{\tau}\left(\lambda_{d} \cdot \dot{d}^{*}+\ddot{d}^{*}+\left(\frac{D}{M}-\lambda_{d}\right) \cdot v+\frac{1}{M} \cdot F_{r}\right)
$$

And the discontinuous regulator law written as (15),

$$
i_{q s n}=k_{q} \operatorname{sat}\left(s(d) / \xi_{q}\right)
$$

We choose conditions $\left(s_{1} \cdot \dot{s}_{1}<0, s_{2} \cdot \dot{s}_{2}<0\right)$ to prove the system stability, it is adequate to select the gain $k_{q}$ strictly positive and sufficiently large.

\subsubsection{Design of sliding mode current controllers}

In this design we used two sliding mode controllers to regulate the d-axis and q-axis secondary currents respectively. The design consists of two steps. One, we define sliding surfaces $s=\left[\begin{array}{ll}s_{1} & s_{2}\end{array}\right]=0$ as (16).

$$
\begin{aligned}
& s_{1}: s\left(i_{d s}\right)=i_{d s}^{*}-i_{d s} \\
& s_{2}: s\left(i_{q s}\right)=i_{q s}^{*}-i_{q s}
\end{aligned}
$$


Where $i_{d s}^{*}$ and $i_{q s}^{*}$ is the reference value of the d-axis and $q$-axis secondary currents, respectively. If the system stays stationary on the surface, then we obtain $s_{1}=s_{2}=0$. Substituting (10) into $s_{1}=0$ and $s_{2}=0$ yields,

$$
\begin{aligned}
& i_{d s}=i_{d s}^{*} \\
& i_{q s}=i_{q s}^{*}
\end{aligned}
$$

Secondly, voltage control law that forces the system to move towards the sliding surface in a finite time. Differentiating $s_{1}$ and $s_{2}$ with respect to time gives (18).

$$
\begin{aligned}
& \dot{s}_{1}=\dot{s}\left(i_{d s}\right)=\dot{i}_{d s}^{*}-\dot{i}_{d s} \\
& \dot{s}_{2}=\dot{s}\left(i_{i q s}\right)=\dot{i}_{q s}^{*}-\dot{i}_{q s}
\end{aligned}
$$

Taking into account the equations of the permanent magnet linear synchronous motor in (1) and (2), the reference voltages control laws can be writing as (19), (20) and (21).

$$
\begin{aligned}
& s\left(i_{d s}\right)=\left(i_{d s}^{*}-\left(-\frac{R_{g}}{L_{d I}} i_{d s}+\frac{L_{q}}{L_{d I}} \frac{\pi}{T} P \cdot v \cdot i_{q s}+\frac{1}{L_{d I}} v_{d s}^{*}\right)\right) \\
& s\left(i_{q S}\right)=\left(i_{q S}^{*}-\left(-\frac{R_{x}}{L_{\mathrm{q}}} i_{q}-\frac{\pi}{\tau} v i_{\mathbb{Q}}-\frac{\psi \tau}{L_{q q} \tau} v+\frac{1}{L_{\mathrm{qq}}} v_{q S}^{*}\right)\right)
\end{aligned}
$$

We take: $i_{s}=i_{s e q}+i_{s n}$

In the sliding mode and at steady-state conditions, we have $s_{1}=s_{1}=0, s_{2}=s_{2}=0, v_{d s n}=0$ and $v_{G s n}=0$ the equivalent control actions presents as (22) and (23).

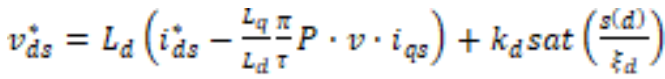

$$
\begin{aligned}
& v_{q s}^{*}=L_{q}\left(i_{q s}^{*}+\frac{R_{x}}{L_{q q}} i_{q}+\frac{\psi \pi}{L_{q q} \tau} P \cdot v\right)+k_{q} \operatorname{sat}\left(\frac{s(d)}{k_{q q}}\right)
\end{aligned}
$$

The Figure 2 presents the block diagram of PMLSM control using sliding mode control.

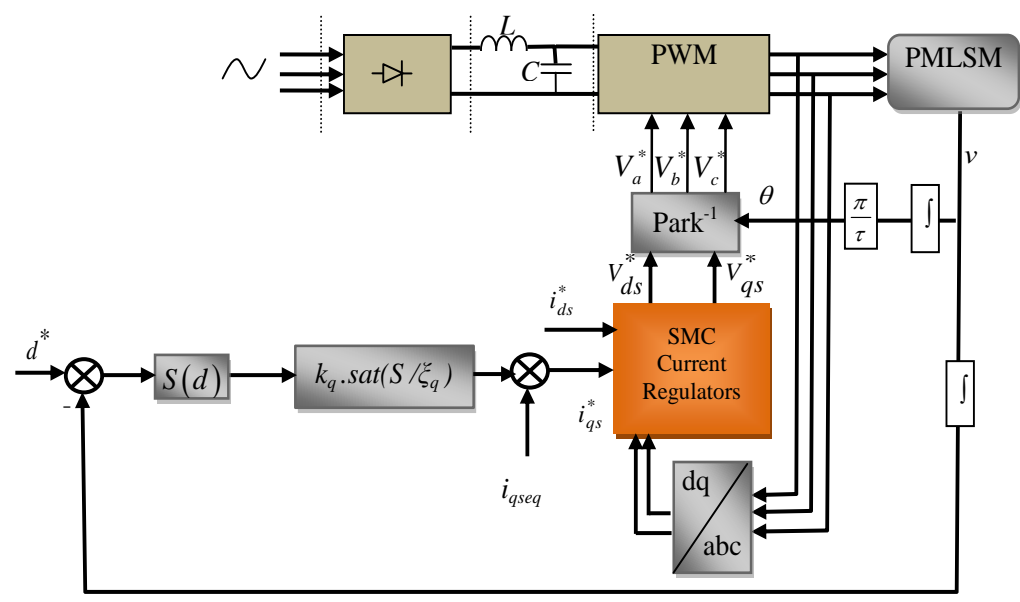

Figure 2. Block diagram of Sliding mode position and currents control of PMLSM motor 


\subsection{Adaptive fuzzy-based sliding mode control}

The disadvantage of sliding mode controllers is that the discontinuous control signal produces chattering dynamics. In order to eliminate the chattering phenomenon, different schemes have been proposed in the literature [13], [14], [17]-[19], [22]-[24]. The most known solutions are those which propose to replace the signum function by a saturation function or a hyperbolic tangent [18]. However, we must find a compromise between the tracking error and the thickness of the boundary layer [6] , [20], [25], [26]. In order to overcome the disadvantages of the SMC controller and to ensure good responses in closed loop control with high possible attenuation of the chattering phenomenon, we propose in this section a combination approach between the Fuzzy logic and SMC. The new adaptive SMC controller based on fuzzy logic has the same control law as the classical SMC, but the parameters $k$ and $\xi$ of the switching control given in (9) are adjusted by a fuzzy logic inference system. The adaptive fuzzy sliding mode controller works in such way that when $s$ and $\dot{s}$ are big, $k$ and $\xi$ take a high values, when $s$ and $\dot{s}$ are small, $k$ and $\xi$ take a low values.

The scheme of the proposed adaptive sliding mode using fuzzy logic for PMLSM position control is showns in Figure. 3. The fuzzy logic controller works as an adaptive system of the switching control part of the SMC. In the proposed fuzzy-SMC scheme, the sliding surface $(s)$ and its time derivative $\dot{s}$ form the input space of the fuzzy logic adapter whereas the adaptive gain $\alpha$ represents the output of the fuzzy adapter. Therefore, the discontinuous control law of (9).

$$
i_{q s n}^{f}=k_{f} \cdot \operatorname{sat}\left(s(d) / \xi_{f}\right)
$$

With

$$
\left\{\begin{array}{l}
k_{f}=\alpha \cdot k_{q} \\
\xi_{f}=\alpha \cdot \xi_{q}
\end{array}\right.
$$

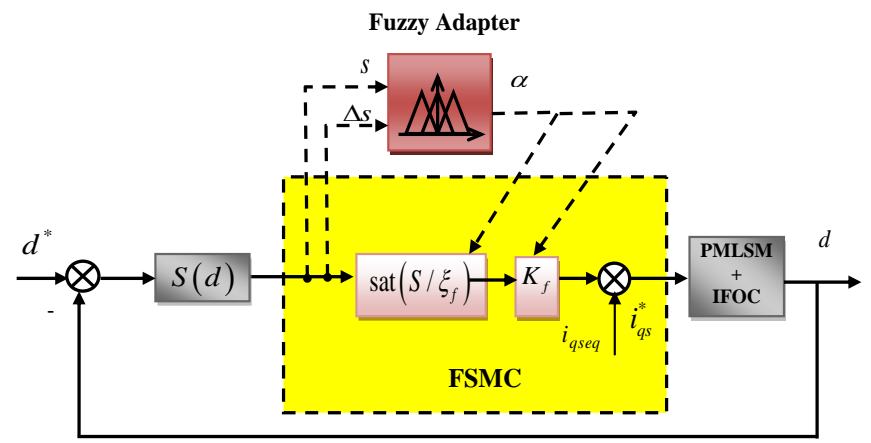

Figure 3. The proposed adaptive SMC control using fuzzy logic (AFSMC)

The membership functions for the inputs $s$ and $\dot{s}$ are defined in the range $[-1,1]$ (see Figure 4), and for the outputs are defined in the range $[0.8,1.6]$ (see Figure 5). The fuzzy subsets of the input variables are defined as follows: Negative (N), Zero (Z) and Positive (P). The fuzzy adapter subsets of the output variable are defined as: Negative High (NH), Negative Big (NB), Negative Medium (NM), Negative Small (NS), Zero (ZE), Positive Small (PS), Positive Medium (PM), Positive Big (PB), Positive High (PH). The fuzzy rules governing the gain adaptation law of $k_{f}$ and $\xi_{f}$ are presented as Table 1. The result of saturation function for some different values of $\alpha$ (i.e different values of $k_{f}$ and $\xi_{f}$ ) are shown in Figure 6. 


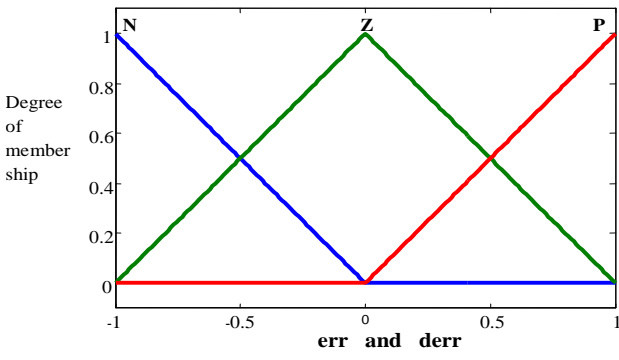

Figure 4. Input membership functions $s \& \dot{s}$

Table 1.The fuzzy logic adapter rules

\begin{tabular}{cccc}
\hline $\boldsymbol{S}$ & $\mathrm{N}$ & $\mathrm{Z}$ & $\mathrm{P}$ \\
\hline $\mathrm{N}$ & $\mathrm{NH}$ & $\mathrm{NS}$ & $\mathrm{PM}$ \\
$\mathrm{Z}$ & $\mathrm{NB}$ & $\mathrm{Z}$ & $\mathrm{PB}$ \\
$\mathrm{P}$ & $\mathrm{NM}$ & $\mathrm{PS}$ & $\mathrm{PH}$ \\
\hline
\end{tabular}

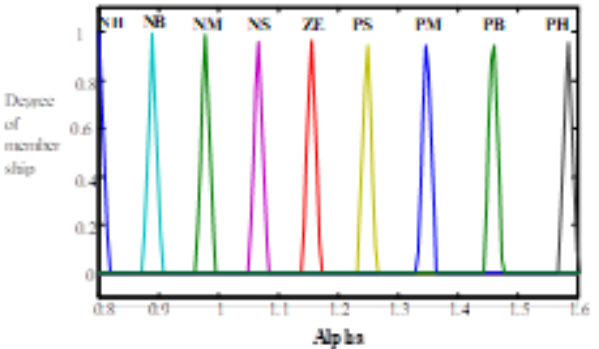

Figure 5. Output membership function $\alpha$

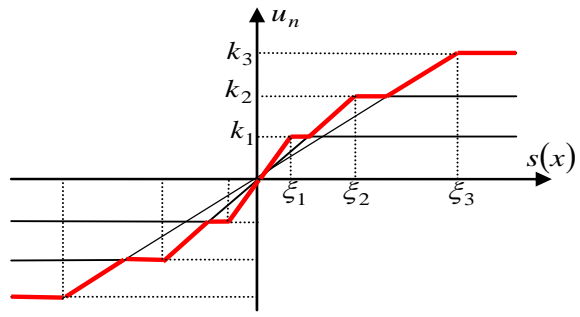

Figure 6. Saturation function for different values of

$$
k_{f} \text { and } \xi_{f}
$$

\section{RESULTS AND DISCUSSION}

We used MATLAB/SIMULINK to carry results for demonstrate the effectiveness of the proposed control scheme for position control of the Permanent magnet linear synchronous motors. To attest the rightness and effectiveness of the proposed theory, we apply the designed controllers to the position control of the PMLSM motor. The machine parameters used in simulation are chosen as: $P_{n}=1380 \mathrm{~W}, U_{n}=130 \mathrm{~V}, I_{n}=2.7 \mathrm{~A}, P=2, R_{s}=1.32 \Omega, L_{d}=11 m \mathrm{H}, L_{q}=11 m \mathrm{H}, M=20 \mathrm{Kg}$, $\tau=30 \mathrm{~mm}, \psi=0.65 \mathrm{~Wb}, D=2 \mathrm{Nm} \cdot \mathrm{s} / \mathrm{rd}$.

First, the simulated results clarify the proposed adaptive fuzzy-sliding mode control system for a rectangular shape-thrust command input and step for position control reference of $\pm 0 \cdot 1 \mathrm{~m}$. The system is operated with no load and then applied a load of $F_{r}=250 \mathrm{~N}$ at time $t=1.5 \mathrm{sec}$. The parameter of simulation are $k_{d}=250, k_{q}=28, \xi_{d}=5, \xi_{q}=0.01, \lambda=125$. These parameters are operating to reach the best transient control performance in simulation considering the requirement of stability and possible operating conditions. The position responses, the phase current $\left(i_{a s}\right)$, the direct and quadratic currents $\left(i_{d s}\right.$ and $\left.i_{q s}\right)$ and the control effort are shown in Figure 7(a), Figure 7(b), Figure 7(c) and Figure 7(d) respectively.

The load disturbance is rejected by the fuzzy sliding controller mode with error that is negligibly called steady state error. The clear observation is seen in the suggested Adaptive Fuzzy- SMC controller offers favorable tracking results with respect to the application of external force, response time and overshoot, we can also see that the chattering phenomen on is very reduced in the control effort as a function of the adjustment of the limit band values and the gain of the discontinuous command while keeping the stability of the system and the setting precision.

The time variation of the switching control law parameters $\left(k_{f}\right.$ and $\left.\xi_{f}\right)$ are shown in Figure 8 (a) and Figure $8(\mathrm{~b})$ respectively, it is noted that the parameters $\left(k_{f} \& \xi_{f}\right)$ vary during the transient control and its take its positions with stability at their values chosen in the SMC mode control. Whereas the phase plane trajectory of the error state for Adaptive FSMC controller is shown in Figure 9, it can be seen that perfect control performances are given by the suggested schemes and this is how the robustness of a controller can be judged and the chattering phenomenon is highly reduced while ensuring stability, robustness and improved machine performance.

Figure 10 shows a comparison between the classical Siding and Adaptive Fuzzy Sliding mode regulator. It shows clearly that the Fuzzy Sliding mode control provide a good control performance compared 
to the classical SMC and the phenomenon of chattering is very reduced by one way remarkably. The load disturnances are rejected by the FSMC adaptive controllers and no overshoot is seen rapidly with the error state. In Figure 11, the classical sliding mode controller is shown:

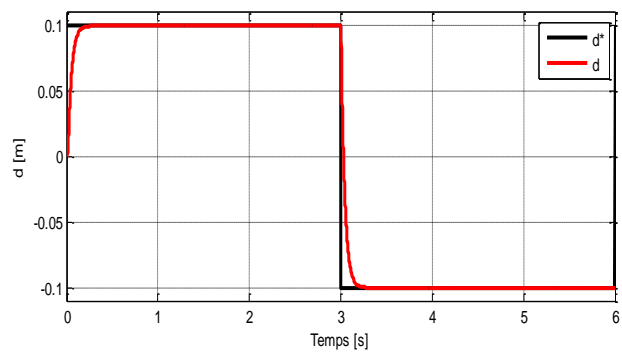

(a)

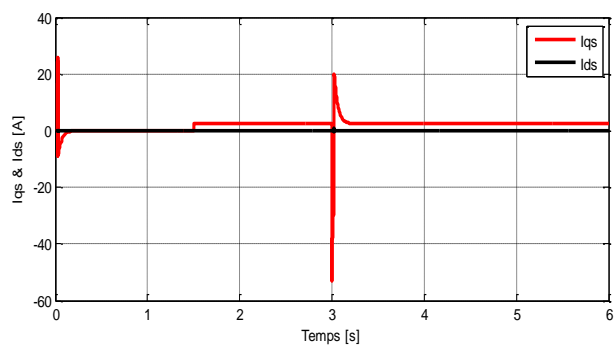

(c)

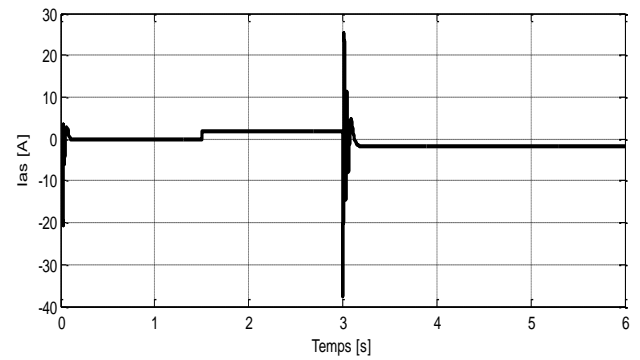

(b)

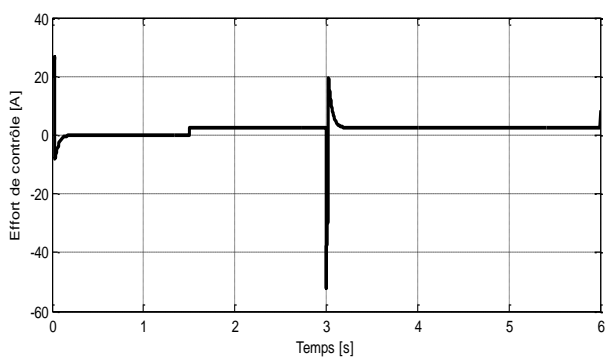

(d)

Figure 7. Simulated results of adaptive FSMC controller for PMLSM, position responses, phase current $\left(i_{a s}\right)$, direct and quadratic currents $\left(i_{d s} \& i_{q s}\right)$ and control effort

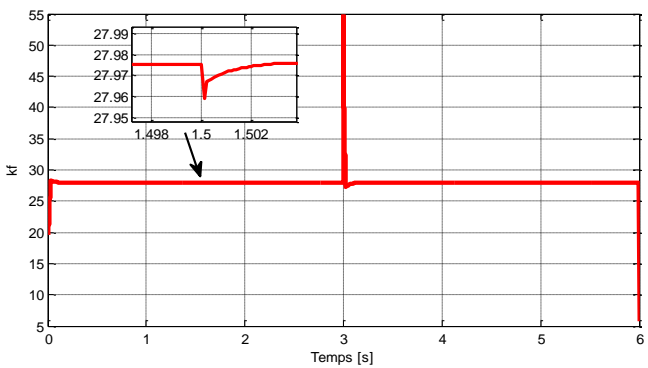

(a)

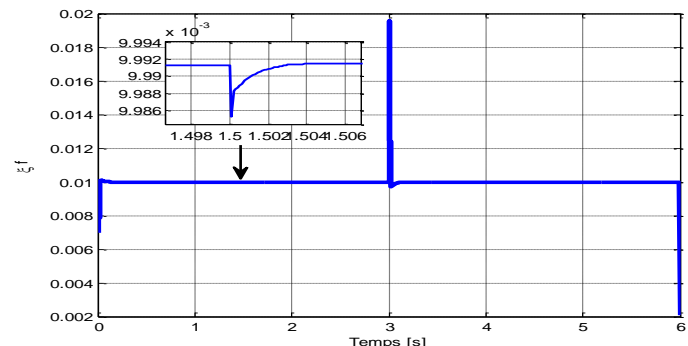

(b)

Figure 8. Parameters variation $k_{f}$ and $\xi_{f}$ of the adapter alpha

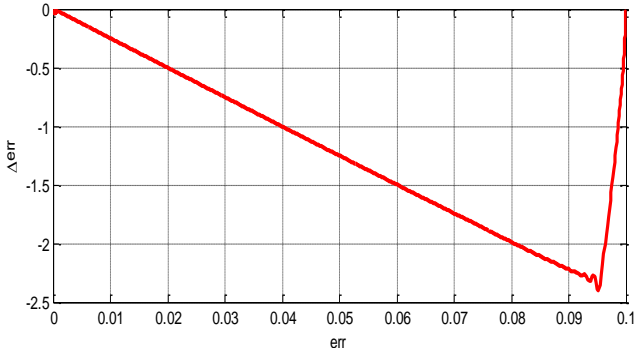

Figure 9. Trajectory of the state in the phase plane for adaptive FSMC controller

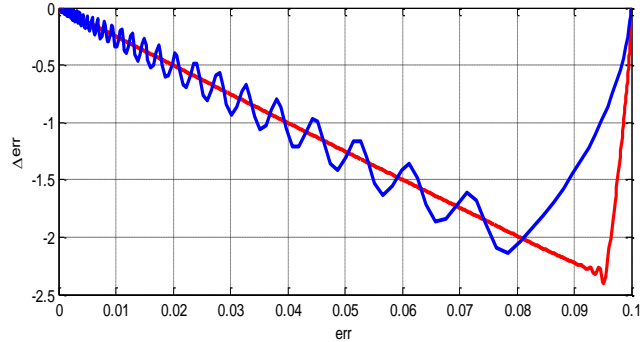

Figure 10. Comparison between trajectory of the state in the phase plane SMC and adaptive FSMC controller 


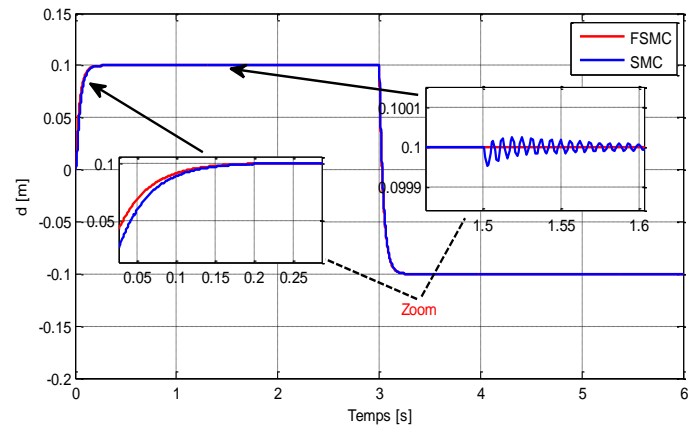

Figure 11. Comparison between classical SMC and adaptive FSMC mode position control of PMLSM

\section{CONCLUSION}

There were some disadvantages of SMC controllers, and it has been proven in this paper that they hybrid fuzzy controller and SMC controller can be applied on SMC controllers to overcome all these disadvantages. In the initial state, an adaptive SMC is obtained on the basis of fuzzy logical tuning. The designing and implementing the adaptive FSMC is attested successfully in this current study for the PMSLM position control. The perfect performances are seen in the schemes suggested as there are some key benefits of using it such as there is a minimal time to rise, no overshoot, better disorder rebuffing, decoupling in excellent form and due to all these factors, the suggested scheme works efficiently for the disturbances in external forces that are timely variable. Higher performance and controller robustness is obtained by the outcomes of different simulation. A dynamic response is obtained by the position control and there is no zero-state steady error and no overshoot as well.

In the end, there is a significant decline in the chattering performance. This also ensures the improved and enhanced performance of machines, stability and robustness with the help of FSMC suggested adaptive technique in contrast to the traditional and classical control of the sliding mode.

\section{REFERENCES}

[1] K. Yoshida, H. Takami, X. Kong, and A. Sonoda, "Mass reduction and propulsion control for a permanent linear synchronous motor vehicle," IEEE Transactions on Industry Applications, vol. 37, no. 1, pp. 62-72, Jan/Feb 2001, DOI: $10.1109 / 28.903128$.

[2] T.H. Liu, Y. C. Lee, and Y.H. Chang, "Adaptive controller design for a linear motor control system," IEEE Transactions on Aerospace and Electronic Systems, vol. 40, no. 2, pp. 601 - 616, April 2004, DOI: 10.1109/TAES.2004.1310008.

[3] G.Lirong and Y. Junyou, "Permanent magnet linear synchronous motor drive using adaptive backstepping sliding mode control," International Conference on Computer and Electrical Engineering, 20-22 Dec. 2008, DOI: 10.1109/ICCEE.2008.170.

[4] Vivek V. Puranik and Vijay N. Gohokar, "Simulation of an Indirect Rotor Flux Oriented Induction Motor Drive using Matlab/Simulink," International Journal of Power Electronics and Drive System (IJPEDS), vol. 8, no. 4, pp. 1693 - 1704, December 2017, DOI: 10.11591/ijpeds.v8.i4.pp1693-1704.

[5] M. S. Kumar, "Permanent magnet linear synchronous motor drive using nonlinear control," International Journal of Engineering Research \& Technology (IJERT), vol. 1, no. 5, July 2012.

[6] Chiranjit Sain, Atanu Banerjee, and Pabitra Kumar Biswas, "Comparative performance study for closed loop operation of an adjustable speed permanent magnet synchronous motor drive with different controllers," International Journal of Power Electronics and Drive System (IJPEDS), vol. 7, no. 4, pp. 1085 - 1099, December 2016, DOI: 10.11591/ijpeds.v7.i4.pp1085-1099.

[7] Qiang Song and Chao Jia, "Robust speed controller design for permanent magnet synchronous motor drives based on sliding mode control," Energy Procedia, vol. 88, pp. 867-873, 2016, DOI: 10.1016/j.egypro.2016.06.102.

[8] Amjad Jaleel Humaidi and Akram Hashim Hameed, "PMLSM position control based on continuous projection adaptive sliding mode controller," Systems Science \& Control Engineering, vol. 6, no. 3, pp. 242-252, 2018, DOI: 10.1080/21642583.2018.1547887.

[9] Jurifa Mat Lazi, Zulkifilie Ibrahim, MHN Talib, Azrita Alias, Ainain Nur and Maaspaliza Azri, "Speed and position estimator for sensorless of PMSM drives using adaptive controller," International Journal of Power Electronics and Drive Systems (IJPEDS), vol. 10, no. 1, pp. 128-136, March 2019, DOI: 10.11591/ijpeds.v10.i1.pp128-136.

[10] Urbanski, Konrad, Zawirski, and Krzyszt, "Adaptive observer of rotor speed and position for PMSM sensorless control system," COMPEL International Journal of Computations and Mathematics in Electrical (COMPEL), vol. 23, no. 4, pp. 1129-1145, 2004, DOI: 10.1108/03321640410510848. 
[11] Igor M. Boiko, "Analysis of chattering in sliding mode control systems with boundary layer approximation of discontinuous control," American Control Conference, San Francisco, CA, USA IEEE, pp. 757-762, 29 June-01 July 2011, DOI: 10.1109/ACC.2011.5990793.

[12] Ganapathy Ram and Santha K R, "Review of sliding mode observers for sensorless control of permanent magnet synchronous motor drives," International Journal of Power Electronics and Drive Systems (IJPEDS), vol. 9, no. 1, pp. 46-54, March 2018, DOI: 10.11591/ijpeds.v9.i1.pp46-54.

[13] Pablo J. Prieto, Nohe R. Cazarez-Castro, Luis T. Aguilar, and Dianelis. Garcia, "Fuzzy slope adaptation for the sliding mode control of a pneumatic parallel platform," International Journal of Fuzzy Systems (Springer), vol. 19, no. 1, pp. 167-178, February 2016, DOI: 10.1007/s40815-016-0163-3.

[14] Ahmed F, Amer, Elsayed A Sallamb, and Wael M. Elawady, "Adaptive fuzzy sliding mode control using supervisory fuzzy control for 3 DOF planar robot," Applied Soft Computing, vol. 11, no. 8, pp. 4943-4953, December 2011, DOI: 10.1016/j.asoc.2011.06.005.

[15] Kais Jamoussi, Mohamed Ouali, and Hassen Charradi, "A sliding mode speed control of an induction motor," American Journal of Applied Sciences, vol. 12, no. 4, pp. 987-994, 2007, DOI: 10.3844/ajassp.2007.987.994.

[16] A Fezzani, S Drid, A Makouf, L Chrifi, and M Ouriagli, "Speed sensoless robust control of permanent magnet synchronous motor based on second-order sliding-mode observer," Serb. J. Electr. Eng, vol. 11, no. 3, pp. 419433, 2014, DOI: 10.2298/SJEE1403419F.

[17] Pablo J. Prietoa, Nohe R. Cazarez-Castroa, Luis T. Aguilarb, and Selene L. Cardenas-Maciela, "Chattering existence and attenuation in fuzzy-based sliding mode control," Engineering Applications of Artificial Intelligence, vol. 61, pp. 152-160, 2017, DOI: 10.1016/j.engappai.2017.03.005.

[18] Lotfi Chaouechi, Moez Soltani, Slim Dhahri, and Abdelkader Chaari, "An optimal fuzzy sliding mode controller design based on particle swarm optimization and using scalar sign function," Iranian Journal of Fuzzy Systems, vol. 14, no. 4, pp. 67-85, 2017, DOI: 10.22111/IJFS.2017.3326.

[19] Ali Saghafinia, Hew Wooi Ping, and M. Nasir Uddin, "Fuzzy sliding mode control based on boundary layer theory for chattering-free and robust induction motor drive," Int J Adv Manuf Technol (Springer), vol. 71, pp. 5768, November 2013, DOI: 10.1007/s00170-013-5398-7.

[20] Fayçal Mehedi, Lazhari Nezli, Mohand Oulhadj Mahmoudi, and Abdelkadir Belhadj Djilali, “A hybrid of sliding mode control and fuzzy logic control for a five-phase synchronous motor speed control," International Conference in Artificial Intelligence in Renewable Energetic Systems(ICAIRES), Renewable Energy for Smart and Sustainable Cities (Springe)r, Cham, vol. 62, pp. 199-205, November 2018, DOI: 10.1007/978-3-030-047894_22.

[21] Fardila Mohd Zaihidee, Saad Mekhilef, and Marizan Mubin, "Robust speed control of PMSM using sliding mode control (SMC)," A Review( Energies ), vol. 12, no. 3, pp. 1-27 (1669), May 2019, DOI: 10.3390/en12091669.

[22] Ali Saghafinia, Hew Wooi Ping, Mohammad Nasir Uddin, and Khalaf S. Gaied, "Adaptive fuzzy sliding-mode control into chattering-Free IM drive," IEEE Transactions on Industry Applications, vol. 51, no. 1, pp. 692-701, January/February 2015, DOI: 10.1109/TIA.2014.2328711.

[23] Larbi M'hamedl, Adjir Roufaida, and Ait Ameur Mezyane Nawal, "Sensorless control of PMSM with fuzzy model reference adaptive system," International Journal of Power Electronics and Drive Systems (IJPEDS), vol. 10, no. 4, pp. 1772-1780, December 2019, DOI: 10.11591/ijpeds.v10.i4.pp1772-1780.

[24] Kheira Belgacem, Abelkader Mezouar, and Najib Essounbouli, "Design and analysis of adaptive sliding mode with exponential reaching law control for double-fed induction generator based wind turbine," International Journal of Power Electronics and Drive System (IJPEDS ), vol. 9, no. 4, pp. 1534-1544, December 2018, DOI: 10.11591/ijpeds.v9.i4.pp1534-1544.

[25] Arun Prasad K. M and Usha Nair, "Intelligent fuzzy sliding mode controller based on FPGA for the speed control of a BLDC motor," International Journal of Power Electronics and Drive System (IJPEDS), vol. 11, no. 1, pp. 477-486, March 2020, DOI: 10.11591/ijpeds.v11.i1.pp477-486.

[26] R. Gunabalan and V. Subbiah, "Speed sensorless vector control of induction motor drive with PI and fuzzy controller," International Journal of Power Electronics and Drive System (IJPEDS), vol. 5, no. 3, pp. 315-325, February 2015, DOI: 10.11591/ijpeds.v5.i3.pp315-325.

\section{BIOGRAPHIES OF AUTHORS}

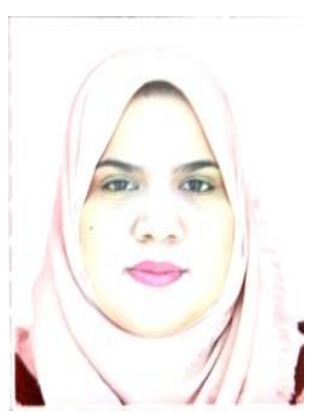

Makhloufi Khadidja received the state engineer degree in Electrical Engineering in 2006 from the University Tahri Mohammed of Bechar Algeria. She received her Magister in electrical engineering in 2014 from the same University. Her research interests include electrical machines and drives, robust adaptive control and observer techniques, she is currently member in smart Grid and Renewable Energy Laboratory, University Tahri Mohamed of Bechar, BP 417 Bechar Algeria 


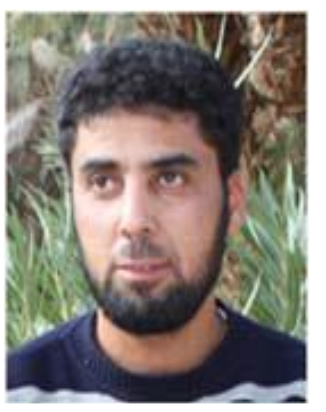

Bouserhane Ismail Khalil was born in Bechar, Algeria, in 1976. He received his BS degree in electrical engineering from the Electrical Engineering Institute of the University Centre of Bechar in 2000.He received the M.S. degree and the PhD degree in Electrical Engineering from the University of Sciences and Technology of Oran (Algeria), in 2003 and 2008, respectively, $\mathrm{He}$ is currently Professor of electrical engineering at University of Bechar, Algeria. His areas of interest are modern control techniques and their application.

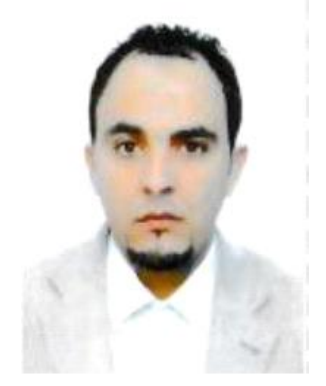

Zegnoun Si Ahmed received the state engineer degree in Electrical Engineering in 2005 from the University of Bechar. He was born his Magister and the $\mathrm{PhD}$ degree in electrical engineering from University of Sciences and Technology of Oran (USTO), BP 1505 Bir El Djir 31000 Oran, Algeria, in 2013 and 2019 respectively. His research area interests are power electronics, FACTS, HVDC, power quality issues and energy storage. 